\title{
Empiricism Must, but Cannot, Presuppose Real Causation
}

\author{
Hans Radder ${ }^{1}$ \\ Accepted: 5 January 2021 / Published online: 8 April 2021 \\ (C) The Author(s) 2021
}

\begin{abstract}
In this article, I put forward a basic philosophical claim: empirical scientific knowledge, that is, knowledge generated in experimental and observational practices, presupposes real causation. My discussion exploits two core notions from the philosophical analysis of scientific experimentation and observation: the aim of realizing object-apparatus correlations and the required control of the relevant interactions between environment and experimental or observational system. The conclusion is that, without the notion of real causation, acquiring epistemically sound empirical knowledge is impossible. Several empiricist objections to this conclusion are discussed and refuted. As a consequence, empiricism faces an unsolvable dilemma: either it cannot account for empirical knowledge or it should accept the existence of unobservable but real causal interactions.
\end{abstract}

Keywords Science in practice $\cdot$ Empirical knowledge $\cdot$ Real causation $\cdot$ Empiricism

\section{Introduction}

The philosophical and scientific significance of the notion of causation has been frequently questioned, primarily by philosophers in the empiricist tradition. The basic assumptions of empiricism are that sensory experience constitutes the foundation of all knowledge and that belief in the reality of unobservable entities, properties, events or processes cannot be epistemologically justified. Claims about unobservables may have some pragmatic function in human discourse or human affairs, but they tell us nothing about the real world.

Causation is a prime target of the empiricist criticism of the reality of unobservables. ${ }^{1}$ As David Hume argued long ago, causation cannot be observed. Therefore, the claim that real causation exists and occurs in objective processes in the world should not play a part in any sound philosophical or scientific reasoning. The early Bertrand Russell agreed and stated that the notion of cause should be completely removed from

\footnotetext{
1 To avoid confusion, when I speak about causation in this article, I mean 'real causation', in the sense explained in the following section. In cases of other interpretations, in particular the empiricist interpretation, I will add a qualification and speak of 'empiricist causation'.
}

Hans Radder

H.Radder@vu.nl

1 Department of Philosophy, VU University Amsterdam, Amsterdam, The Netherlands 
our philosophical vocabulary. Among current philosophers of science, Bas van Fraassen and David Papineau endorse empiricist critiques of real causation.

In addition, Russell advocated the more specific claim that our most advanced scientific theories, the theories of mathematical physics, are no more than formulas that do not contain any reference to causation. In fact, they are even time-symmetric, and therefore at odds with the fundamental time asymmetry between cause and effect (Russell 1963[1917], 140-144). This claim is accepted by a significant number of wellknown contemporary philosophers of science, who may not all be strict empiricists but who are nonetheless skeptical about a role for causation in physics. Matthias Frisch, who himself argues that the arguments for causal eliminativism in physics are unconvincing, mentions Patrick Suppes, Richard Healey, Bas van Fraassen, Hartry Field, Huw Price, John Norton and John Earman (Frisch 2012, 313-314).

A typical feature of empiricism is the belief that the notion of the empirical is philosophically unproblematic and can therefore be used as the basis for ordinary and scientific knowledge claims. This explains why empiricists do not pay much attention to the study of empirical practices in science or ordinary life (Radder 2006, Ch. 2). Fortunately, many other philosophers have provided in-depth and sustained studies of such practices. During the last four decades, many detailed studies of scientific experimentation and observation have been made available (see, e.g., Hacking 1983; Kosso 1989; Galison 1997; Janich 1998). Similarly, many accounts of ordinary empirical practices have been provided through a variety of specific studies of embodied and embedded cognitive processes (see, e.g., O’Regan and Noë 2001; Anderson 2003). What these studies have demonstrated is that empirical knowledge, both in science and in ordinary life, is the result of complex practices. For this reason, such knowledge cannot be conceived as philosophically unproblematic or neutral. The central insight is that obtaining experience may fail as a matter of course and not merely in the case of individual illusions or hallucinations. With respect to science the point can also be phrased somewhat differently, as follows. Experimental and observational evidence is not 'given' but has to be correctly realized. This entails that epistemology needs to address the question of the justification of evidence. The epistemology of science cannot be limited to the issue of how 'given' evidence justifies theoretical claims.

The focus of this article is on scientific experience (but an extension of its conclusion to ordinary experience seems plausible). I do not presuppose the specific views of the authors cited in the preceding paragraph. I merely use their general point that in-depth study of empirical practices in science and ordinary life may lead to novel philosophical insights and may undermine traditional views and doctrines. If we take into account this point, the empiricist critique of the notion of causation proves to be untenable.

In the next section I argue, for the case of science, that the existence of causation, in the form of real causal interaction, is a precondition of obtaining sound experimental and observational knowledge. Section 3 first explains the empiricist position in more detail and then discusses and refutes several possible empiricist objections to the argument presented in Sect. 2. The final section summarizes my conclusions. To avoid misunderstanding, in this article I do not intend to present a detailed account of causation. As its title indicates, my primary aim is a fundamental critique of empiricism. As we will see, for this purpose a rough and ready account of the notion of real causation suffices. 


\section{Acquiring Empirical Knowledge Requires the Notion of Real Causation}

The empirical processes of experimentation and observation form an essential part of the sciences and their study offers a wealth of rich material for philosophical analysis and reflection. In particular, intervention or, more generally, material realization is a crucial aspect of empirical science. Experimentation includes the material realization of a process, that is, a spatially extended experimental system that develops over time. ${ }^{2}$ The same applies to scientific observation, which is almost always mediated through technological apparatus.

Suppose we would like to acquire some knowledge of an object $O$. In the case of empirical science, this requires an interaction between $O$ and some detection apparatus $A$. Often, $O$ needs to be suitably prepared and $A$, or parts of it, newly designed. The apparatus may also be, or include, a model organism, a laboratory animal, a research subject, or the human observer itself. The basic idea underlying the generation of empirical knowledge is that we try to realize the interaction between $O$ and $A$ in such a way that a complete (or at least a strong) and stable correlation arises between certain features of $O$ and the final state of $A$. In terms of the interaction-information theory of observation, the interaction between $O$ and $A$ produces specific information about $O$ which is being registered on apparatus $A$. In this indirect, mediated manner, experiments and observations allow us to acquire empirical knowledge of $O$ by reading the final state of the apparatus.

In order to be able to conclude that the resulting state of $A$ tells us something specific about $O$ we also have to take into account the interactions between the experimental or observational $O+A$-system and its environment. We need to take care, through actual intervention and control, that external factors will not influence this system in a way that may spoil the design and aim of the experiment or observation. Thus far, this analysis is rather abstract, but it can be fruitfully applied to concrete experiments and observations by specifying the object, the apparatus, the interactions, and the (relevant parts of) the environment. ${ }^{3}$

In descriptive studies of empirical practices the role of causation is often taken for granted. Ian Hacking, for instance, makes explicit use of the notion of causation in his own philosophical claims, in particular in his arguments for entity realism (Hacking 1983, 146, 265 and 272), but he does not provide a separate philosophical defence of this notion. Apparently, he seems to take a reference to the explicit and implicit uses of causation by experimental scientists as being argument enough.

Yet, I think that such a defence is desirable and that it is possible by focusing on the processes of material realization. This emphasis on the significance of material realization agrees with Hacking's criticism of a theory-dominant view of science. He sees Karl Popper as a typical proponent of such a view and illustrates this with a long quotation of Popper's view of the relation between experiment and theory (Hacking 1983, 155). Remarkably enough, in this quotation Hacking has skipped precisely that part of the passage in which Popper (himself loosely quoting Hermann Weyl) does say something sensible regarding

\footnotetext{
${ }^{2}$ Radder (2012[1984/1988], 62-69 and 166-169) and (2009, 79-83). An advantage of the term 'realization' is that it may refer both to the process of intervention and to its products.

3 See Radder (2012[1984/1988], Ch. 3 and Postscript; 1996, Chs. 2 and 6; 2006, Ch. 7; 2009, Sect. 5). Another important notion, the further processing of data and other empirical results, is not immediately relevant to the arguments of this article.
} 
experimental work, namely that "[p]art of this work consists in screening off all possible sources of error" (Popper 1965[1934], 107). More generally, the distinction between the experimental $O+A$-system and its environment, and the subsequent requirement to control the interactions between the experimental system and the relevant aspects of this environment do not play a systematic role in Hacking's account of scientific experimentation. ${ }^{4}$

The argument for the essential role of causation derives from this requirement of excluding potentially disturbing external influences on the $O+A$-system. It goes like this. Without stable and reproducible experimental or observational results, we do not have good reasons to believe the (empirical and theoretical) knowledge claims of the sciences. Successful experimentation and observation, however, is not possible without the notion of real causation. Suppose again that we would like to acquire some knowledge of object $O$ by connecting it to apparatus $A$. As we have seen, we need to realize an interaction between $O$ and $A$ in such a way that an observable outcome of $A$ allows us to infer reliably some feature of $O$. To be sure, empiricists may argue (for instance, on the basis of a non-literal instrumentalist interpretation of the description of the $O+A$-interaction) that this 'interaction' can be consistently interpreted as no more than a correlation. Yet, this is not the full story since there is a second relevant interaction, namely the one between the $O+A$-system and its environment. In addition to the $O+A$-interaction, the material realization of the experiment or observation needs to be such that no factor in the external environment will significantly disturb the $O+A$-system. This epistemic requirement shows that the notion of real causation (in the sense of an actual disturbance) plays a crucial role in obtaining empirical knowledge. In addition, it is important to note that this argument applies both to macroscopic ('observable') and to microscopic ('unobservable') objects $O$.

The point can be illustrated by the following three examples from actual scientific practices. The first is a laboratory experiment in immunological research in the 1970s, described in Latour and Woolgar (1979, 169-170). A specific cell culture assay pertaining to the immune system appeared to work in the original laboratory and some other places but not in several other labs. After some time and through a range of different events a disturbing external cause was discovered, namely a low concentration of selenium in the water used in the experiment. The experiment only worked in those geographical areas of the US where the selenium content of the water was high. Thus, a stable and reproducible experiment required removing the disturbing cause by materially realizing water with a sufficiently high amount of selenium.

The second example concerns a type of field experiment in astronomy. In May 2015, my newspaper included an article headed 'Windmill interferes with telescope' (Van den Berg 2015). In the Dutch countryside, fifty large windmills were planned to be built at a distance of seven kilometers from the largest radio-telescope in the world (the LOFAR, or Low Frequency Array). ${ }^{5}$ Joining the already present NIMBY protests, the astronomers complained that these windmills can be expected to seriously disturb their measurements through the uncontrollable radio and radar signals that will be generated by the mills themselves or will be reflected by their rotating blades. After extensive negotiations, a deal was made between

\footnotetext{
4 The subject is mentioned in passing in two examples (Hacking 1983, 159 and 257).

5 For background information on the realization of this long-term LOFAR project, see Baneke (2020, 182186).
} 
the astronomers and the builders of the windmills. It was agreed that first one would try to prevent the structural disturbances by accurate additional shielding of the windmills. If that proved to be unfeasible, the building of the mills would be discontinued (Van der Heijden 2018). Thus, a successful material realization of the astronomical measurements requires the identification of the interfering causes, followed either by their shielding or by their elimination.

A third example is a spectacular experiment performed in 2015 and 2016, which was awarded the 2017 Nobel Prize for physics. It presented the first convincing evidence for the existence of gravitational waves (or, equivalently, space-time vibrations), a phenomenon that had been predicted long ago by Albert Einstein. Detectors in two observatories recorded the signal of gravitational waves produced 1.3 billion years ago by the collision of two black holes. ${ }^{6}$ This was a big and expensive project in which several teams from all over the world cooperated. In an interview, the leader of the Dutch collaborating team, physicist Jo van den Brand, recounts the following:

That the detectors go off means that there has been a vibration in the [experimental, HR] system. The question is what its cause is. A magnetic thunderstorm? An earthquake? A technological mistake? Indeed a gravitational wave, caused by a violent event somewhere in the universe? Or, who knows, even a joke. Or sabotage (quoted in Van Calmthout 2016, 16, my translation).

Thus, a substantial part of the experimental work consisted, first, of making a list of all kinds of potential disturbances; and then of checking whether they might have been the actual cause of the signal. ${ }^{7}$ It was real detective work, Van den Brand concludes.

The point of the three examples applies to any experiment or observation. Sound empirical knowledge can only result, first, if we assume that there may exist, and probably will exist, external events that may causally disturb the observational or experimental systems (ontology); second, if we succeed in knowing which are the relevant causal interactions (epistemology); and third, if we are able to prevent or eliminate these causal interactions by actual interventions (methodology).Thus, the examples clearly show that acquiring sound empirical knowledge presupposes the epistemological and methodological inevitability of the notion of real disturbances of the experimental or observational system through causal interactions with the environment. Basically, a realist interpretation of these disturbances says that such causal phenomena cannot be, or cannot fully be, explained on the basis of (the results of) human engagement with these phenomena; an adequate philosophical interpretation should, or should also, refer to a reality that is independent of these engagements. Of course, philosophers may further develop and refine the notion of real causal interaction. However, for the purpose of this article,- - a critique of empiricist accounts of causation-the given basic characterization of real causation suffices, as we will see in the next section.

\footnotetext{
6 See Nobel Committee for Physics (2017) for an account of the theoretical background, the design and the performance of the experiment.

7 "High sensitivity to gravitational strain requires not only the minimization of all the many known detector noise sources, but also the monitoring of potential environmental disturbances and their impact on the detectors. To this end the observatory is equipped with thousands of sensors - accelerometers, seismometers, microphones, magnetometers and many others" Nobel Committee for Physics $(2017,10)$.
} 


\section{Empiricist Objections and Their Refutation}

The argument of this section first requires a more detailed description of the empiricist approach to philosophy and to the issue of causation in particular. For this purpose, I also address 'empiricist' views that do endorse the making of causal claims. After that, I discuss, and refute, possible empiricist objections to the argument of the preceding section. Finally, I explain what is, and what is not implied in this argument, both philosophically and scientifically.

\subsection{The Basic Empiricist Stance}

Jennifer Nagel accurately describes the basic empiricist position as follows:

Given the definitive principle of their position, empiricists can allow that one can have knowledge independent of experience only where what is known is not some objective fact about the world, but something about the way it is conceptualized or described (Nagel 2006, 235). ${ }^{8}$

The work of Van Fraassen represents and develops this approach in a lucid and consistent way, as illustrated in the following quotations:

To be an empiricist is to withhold belief in anything that goes beyond the actual observable phenomena, and to recognize no objective modality in nature (Van Fraassen 1980, 202-203).

Concerning the observable world, Van Fraassen $(1989,178)$ states that "we can and do see the truth about many things: ourselves, others, trees and animals, clouds and rivers-in the immediacy of experience." In contrast to the analysis in the preceding section, experience is seen as immediate, unmediated. Being observable means being directly accessible to our senses. Thus, empiricism excludes as observable entities or properties those that are measureable only with the help of technological instruments. Furthermore, the addition of objective modality (another chief target of empiricist criticism) is important for our discussion of causation. In the form of counterfactual conditionals about possibilities, modal statements often feature in explanations of the notion of causation. Finally, regarding science Van Fraassen $(1989,214)$ claims that "causal and modal discourse describes features of our models, not features of the world". Such descriptions, and hence the cited causes, are context-dependent. In practice, "to describe the whole causal net in any connected region, however small, is in almost every case impossible" (Van Fraassen 1980, 124). The pragmatic nature of causal claims, then, consists in the fact that, from a huge and intractable set of potentially relevant events, they pick out those that are seen as salient in the relevant context.

Van Fraassen discusses the issue of causation in relation to the problems of explanation and lawfulness. That is to say, in the context of providing scientific descriptions of explanations and laws. In contrast, the argument presented in the preceding section does not concern explanations and law-statements but epistemic criteria for successful experimentation and observation. And it is not only about description but also about material realization. Yet, it agrees with the claim (endorsed by Van Fraassen but also by many other authors)

${ }^{8}$ See also Wilson $(2006,93-95)$. 
that in actual practices there is a huge and intractable set of potentially relevant causal factors. ${ }^{9}$ Surprisingly enough, it is the latter claim that shall prove to be a crucial one in refuting possible empiricist replies to the argument presented in the previous section.

In a positive sense, empiricists usually interpret causation in terms a correlation (or a regularity, that is, a 100\% correlation) between observable events, added to which is often (but not always) a time asymmetry (the 'cause' precedes its 'effect'). Papineau, for instance, advocates a Humean interpretation of causation in terms of genuine (that is, nonspurious) correlations (Papineau 1991). ${ }^{10}$

The empiricist account of causation and its skepticism about the reality of causes are not limited to empiricism proper. They can also be found in the neighboring doctrines of pragmatism and constructivism. John Dewey, for instance, literally follows the empiricist account of causation in his methodological analysis of social inquiry:

'Causation' is an affair of historical sequence, of the order in which a series of changes takes place. To know cause and effect is to know, in the abstract, the formula of correlation in change, and, in the concrete, a certain historical career of sequential events (Dewey 1927[1954], 201).

In a more radical way, Bruno Latour derives a strong critique of causation from his empirical description of the scientific construction work that is being done in what he calls centres of calculation:

The main consequence of focusing on centres of calculation and on the many practical ways in which they attract and combine information, is a strong rejection of arguments in terms of cause and effect (Latour 1988, 161).

Thus, analogous to the empiricist approach causation is not seen as something happening in the world. Instead, its meaning can be fully understood as a result of specific scientific practices. In contrast to Van Fraassen, Latour sees causal discourse not as a feature of theoretical models but as a construction made and sustained by powerful research centers.

This short review explains the kind of empiricism that is addressed in this article. Some authors, however, explicitly disagree with the basic philosophical views of the empiricists presented above, but still call themselves empiricists. A case in point is Nancy Cartwright. On the one hand, she repeatedly emphasizes the close connection between her views and empiricism (see, e.g., Cartwright 1999, 6, 70, 152-153). On the other hand, her views also constitute "a radical departure from the usual empiricist view about what kinds of facts there are" (Cartwright 1999, 72). The reason for this radical departure is her endorsement of measureable properties (so, not merely observable ones), real causation, non-occurrent capacities, and Aristotelian natures.

A 'puzzling' statement by Hume has given rise to another 'empiricist' account of causation? This account includes counterfactuals as a crucial ingredient, for instance when ' $A$ causes $B$ ' is said to mean, basically, that ' $B$ would not have happened had $A$ not occurred'. The effect is counterfactually dependent on the cause (Psillos 2002, Ch. 3). Thus, these Humeans seem to see the making of counterfactual claims as compatible with the basic

\footnotetext{
9 The fact that in actual practices there will be a large and complex set of causally relevant factors also constitutes a central theme in the INUS theory of causation (see, e.g., Psillos 2002, 87-92; Illari and Russo 2014, 28-31).

${ }^{10}$ From this article, it is not fully clear whether he also endorses the empiricist part of a Humean account of causation, saying that the causal correlation is limited to observable events.
} 
empiricist position. In spite of this, I think that Van Fraassen's criticism of objective modality is fully correct. A consistent empiricism needs to reject the objectivity of counterfactual events referring to real possibilities. By being counterfactual, a counterfactual event is not observable by definition.

This brief discussion of two alternative 'empiricisms' shows that they deviate from the classical empiricist position in important respects. Therefore, whatever one thinks of their problems and merits, they are not the target of the critique of empiricism presented in this article. Now that the relevant notion of empiricism has been clarified, we can move on to the central question of this section: are there convincing empiricist objections to the argument presented in the preceding section?

\subsection{Countering Empiricist Counterarguments}

A first potential reply is to reject the requirement that empirical knowledge claims should be reproducible. However, this would mean to go against a widespread view and practice of the scientists themselves. More importantly, it would also conflict with the basic motivation for the empiricist privilege of observability. From the empiricist perspective, in contrast to subjective or context-dependent beliefs, the distinctive objectivity of empirical knowledge is based on its intersubjective testability and reproducibility.

A second reply might question the main argument of Sect. 2: could the problem of external disturbances not be solved on the basis of an empiricist account of causation? That is to say, could the problem not be solved by requiring that there should be no correlation at all between observable features of the environment and the $O+A$-system? The answer is: no, for two good reasons. The first is that, without the notion of the real impacts of causal interactions, the no-correlation requirement is fully unmotivated. We can only understand why we should make this requirement by presupposing the notion of real causation. The second reason is the primary one. In practice, there will always be many correlations between the $O+A$-system and environment. For example, in the case of an experiment that uses a lot of electricity, there will be some correlation between the experimental runs and the measures on the lab's electricity meter. Or, more generally, there will be a correlation between the running of an experiment and the actions, and even the presence, of the experimenters. And between the running of this experiment and their travel to the laboratory. And so on. And so on. Moreover, those empiricists who do not believe in the temporal asymmetry of causation should also take into account the many correlations between the running of the experiment and all later events in the environment.

Faced with the problem of potential disturbances, we need to establish which of the (in principle infinite number of) relations between environment and $O+A$-system are epistemically irrelevant and which are relevant. In general terms, three types of epistemically irrelevant relations can be distinguished. First, all those effects of the environment on the experimental or observational system that do not at all disturb the $O+A$-interaction or the working of $A$ itself. Second, all those effects on the $O+A$-system which are negligibly small in view of the aim of the experiment or observation. Third, all those effects of the $O+A$-system on the environment that do not interfere with the appropriate performance of the experiment or observation by the scientists. In all these cases there can be strong correlations, but it will be clear that it is only the notion of real causation that allows us to distinguish between relevant and irrelevant relations. On that basis, we can first select the relevant relations that is, those external events that may causally disturb the intended 
interaction between $O$ and $A$ or the working of $A$ itself, and then try to eliminate or shield these events by actual interventions.

In sum, my primary argument against the second empiricist objection runs as follows: The 'salient' relations are precisely the causal ones, the ones that do or may actually disturb the experimental or observational systems. But empiricists do not believe in real causal disturbances. Furthermore, since the mere notions of correlation and time asymmetry are not enough to select these epistemically relevant relations, they lack this crucial criterion of saliency. Finally, the fact that the relevant interventions need to be actually realized implies that it is not possible to remain agnostic about the reality of the disturbing causal interactions. The only remaining option, then, is to prevent or eliminate all correlations between environment and $O+A$-system, which is endless and therefore practically impossible. The conclusion is that without the notion of real causation epistemically successful scientific experimentation and observation is impossible. ${ }^{11}$ To be sure, empiricists may use certain procedures to reduce the number of correlations, for instance by leaving out the spurious ones or by some other technique. However, a first problem of this specific empiricist counterargument is that such procedures should not be merely pragmatic, because this would make the justification of empirical knowledge claims dependent on pragmatic choices, which goes against the fundamental premise of empiricist epistemology. Second, without adding any realist premises they do not suffice to reduce the huge number of potential correlations between the experimental or observational system and its environment to a practically tractable number. ${ }^{12}$

At this point, empiricists might put forward a third objection and respond that what counts in an epistemic sense is not the $O+A$-interaction or the $O+A$-system as a whole but only the stable empirical data delivered by apparatus $A$. In line with this, they may claim that it is enough to take into account the possible correlations between observable features of the environment and those of the apparatus. Yet, this 'solution' does not work either, since the two reasons for the failure of the empiricist reply that I discussed in the previous paragraphs apply equally to unobservable microscopic and to observable macroscopic systems, such as the observable features of the apparatus. To get stable and reproducible empirical results, we must either eliminate the relevant causal disturbances of the apparatus by factors operating in its environment or effectively shield the apparatus from these factors. As we have seen, the empiricist alternative consisting of eliminating or preventing all correlations, be they observable or not, is both unmotivated and impossible.

Fourthly, empiricists may disagree with my argument for more general reasons. Their ultimate objection might run as follows. With Van Fraassen, they may claim that all theories of causation include context-dependent assumptions and hence are merely 'pragmatic'.

\footnotetext{
11 Note that my point is not a general criticism of the reduction of causes to correlations (although I do agree with this criticism; see, for instance, the critical assessment of Papineau's views in Irzik 1996). Instead, my argument is based on the more specific claim that correlations alone make the justification of empirical knowledge claims unachievable in practice.

12 Papineau, for instance, argues that the multivariate regression techniques in causal modelling constitute a fully adequate correlational account of causation, provided the correlations are reduced to the non-spurious ones (1991). Gürol Irzik, however, convincingly argues that several aspects of this type of causal modelling (the choice and ordering of the explanatory values, the uses of partial correlations, and the assumed features of the so-called error terms) already presuppose some prior causal knowledge that goes beyond the relevant correlations (Irzik 1996, 256-257 and 260-262). What is more, it is even hard to see how empiricists could justify the exclusion of spurious correlations based on the existence of a common cause without smuggling in either pragmatic arguments or a realist interpretation of this cause.
} 
Or they may say that the argument merely shows that acquiring empirical knowledge presupposes causation. Therefore, the argument only concerns the context of discovery. ${ }^{13}$ In this spirit, they might conclude that pragmatic arguments and discovery contexts are not philosophically fundamental or even that they are philosophically irrelevant. This objection, however, misconstrues the nature of the argument. It does not concern pragmatic and as yet unjustified discovery claims, but it makes explicit an ontological condition for obtaining sound scientific knowledge. ${ }^{14}$ Its basic claim is that sound empirical knowledge presupposes real causation. This claim concerns a central issue in epistemology and philosophy of science. Therefore, banishing the argument from philosophy is simply implausible, whatever one may think of the distinction between epistemic and pragmatic matters or between issues of discovery and justification. ${ }^{15}$

Finally, it is important to circumscribe the implications of the argument presented in this article. Philosophically, it is quite different from interventionist arguments claiming that the meaning of causation or the criterion for causal claims can be derived from experimental practice (as proposed, in different ways, by Georg von Wright, Peter Janich and James Woodward, among others). Instead, the argument of this article is that experimentation (and observation) presupposes a specific kind of causation. More generally, my argument does not single out a specific realist theory of causation as the right one. The basic characterization of causation given at the end of Sect. 2 is compatible with a variety of further refinements, for instance in terms of the notions of causal powers (e.g., Bhaskar 1978[1975]), causal processes (e.g., Salmon 1984), or causal mechanisms (e.g., Illari and Russo 2014, Ch. 12).

Scientifically, the argument is about empirical knowledge. It does not tell you whether the models or theories that build on this knowledge will, or should, include causal statements. Therefore, in this and the preceding section I have intentionally left aside the empiricist claims concerning the absence of causation in theoretical science, in particular in mathematical physics. Yet, these claims can be questioned as well. Particularly questionable is the exclusive focus on the formal-mathematical aspects of the equations of theoretical physics, which neglects their conceptual-theoretical meaning (see Radder (2012[1984/1988]). This point has been effectively exploited by Frisch in his criticism of the empiricist claims concerning the role of causation in theoretical physics (see Frisch 2012). However this may be, the present article is limited to empirical knowledge and thus it cannot say who is right in this debate. My reason for mentioning the debate is that the arguments in the preceding sections do entail a simple bonus conclusion. Causal skeptics about theoretical physics often extrapolate their claims by stating, or at least suggesting, "that physics has no place for causes". A corollary of my arguments is that this theoryfocused extrapolation is wrong, because observational and experimental physics do presuppose real causation.

\footnotetext{
13 Compare with Russell (1963[1917], 144); see also Papineau's criticism of drawing metaphysical conclusions from methodological insights (1991, 410-411).

14 Note also that it is not a transcendental condition in the Kantian sense of an a priori requirement of any possible experience, which cannot be empirically violated.

15 Apart from this, since causality plays a crucial and ineliminable role both in ordinary life and in science, technology, engineering and medicine (cf. Illari and Russo 2014), such an account of philosophy would make itself completely irrelevant to what matters, in this respect, to real people in actual practices.
} 


\section{Why Empiricism Must, but Cannot, Presuppose Real Causation}

The claims I have made concerning the nature of causation are of a general kind. The first major conclusion is that the generation of empirical knowledge through materially realizing experimental and observational processes presupposes an ontology of real causation and the justifiability of the epistemic and methodological claims about the absence of relevant causal disturbances. Furthermore, I think it is plausible (although I do not develop the point here) that the argument can be extended from scientific to ordinary experience. After all, in order to be successful ordinary observational processes should be similarly shielded from disturbing causal interactions. Just think of cleaning one's glasses or contact lenses, of airing a damp room that hinders our eyesight, of removing interfering obstacles, or of sending away distracting children who impede focused attention (Radder 2006, Ch. 7). Finally, it will be clear that the notion of causation cannot be reduced to (some features of) successful experimental or observational intervention, since this intervention already presupposes this notion. ${ }^{16}$

The second major conclusion is about empiricism. It is stated in the title of this article: empiricism must, but cannot, presuppose real causation. That is to say, empiricism is caught in a dilemma that is unsolvable because each horn goes against a fundamental empiricist assumption. On the one hand, without real causation there will be no empirical knowledge. On the other hand, belief in real causation is out of the question because causation cannot be observed. This argument is new, straightforward and, I think, hard to refute. The reason for the latter claim is that it is not based on an interpretation of theoretical features of science, which could be contested by empiricists. Instead, it directly results from the empirical character of science, a character that constitutes the core of empiricist philosophy of science. Paraphrasing Hume, my general conclusion is that if we come across an article or book that defends an interpretation of scientific knowledge that makes it impossible to acquire it, "commit it then to the flames: for it can contain nothing but sophistry and illusion".

Acknowledgements Thanks to Sebastian De Haro and Phyllis Illari for helpful comments and suggestions.

Open Access This article is licensed under a Creative Commons Attribution 4.0 International License, which permits use, sharing, adaptation, distribution and reproduction in any medium or format, as long as you give appropriate credit to the original author(s) and the source, provide a link to the Creative Commons licence, and indicate if changes were made. The images or other third party material in this article are included in the article's Creative Commons licence, unless indicated otherwise in a credit line to the material. If material is not included in the article's Creative Commons licence and your intended use is not permitted by statutory regulation or exceeds the permitted use, you will need to obtain permission directly from the copyright holder. To view a copy of this licence, visit http://creativecommons.org/licenses/by/4.0/.

\section{References}

Anderson, M. L. (2003). Embodied cognition: A field guide. Artificial Intelligence, 149(1), 91-130.

Baneke, D. (2020). Let's not talk about science: The normalization of big science and the moral economy of modern astronomy. Science, Technology, \& Human Values, 45(1), 164-194.

Bhaskar, R. (1978[1975]). A realist theory of science. Hassocks: Harvester Press.

Cartwright, N. (1999). The dappled world: A story of the boundaries of science. Cambridge: Cambridge University Press.

$\overline{16}$ On this point, see also Lange (2003, 124-128). 
Dewey, J. (1927[1954]). The public and its problems. Athens: Swallow Press/Ohio University Press.

Frisch, M. (2012). No place for causes? Causal skepticism in physics. European Journal for Philosophy of Science, 2(3), 313-336.

Galison, P. (1997). Image and logic: A material culture of microphysics. Chicago: University of Chicago Press.

Hacking, I. (1983). Representing and intervening. Cambridge: Cambridge University Press.

Illari, P., \& Russo, F. (2014). Causality: Philosophical theory meets scientific practice. Oxford: Oxford University Press.

Irzik, G. (1996). Can causes be reduced to correlations? British Journal for the Philosophy of Science, 47(2), 249-270.

Janich, P. (1998). Was macht experimentelle Resultate empiriehaltig? Die methodisch-kulturalistische Theorie des Experiments. In M. Heidelberger \& F. Steinle (Eds.), Experimental essays - Versuche zum Experiment (pp. 93-112). Nomos: Baden-Baden.

Kosso, P. (1989). Observability and observation in physical science. Dordrecht: Kluwer.

Lange, R. (2003). Technology as basis and object of experimental practices. In H. Radder (Ed.), The philosophy of scientific experimentation (pp. 119-137). Pittsburgh: University of Pittsburgh Press.

Latour, B. (1988). The politics of explanation: An alternative. In S. Woolgar (Ed.), Knowledge and reflexivity (pp. 155-176). London: Sage.

Latour, B., \& Woolgar, S. (1979). Laboratory life: The social construction of scientific facts. Beverly Hills: Sage.

Nagel, J. (2006). Empiricism. In S. Sarkar \& J. Pfeifer (Eds.), The Philosophy of science: An encyclopedia (Vol. 1, pp. 235-243). New York: Routledge.

Nobel Committee for Physics. (2017). The laser interferometer gravitational-wave observatory and the first direct observation of gravitational waves. https://www.nobelprize.org/prizes/physics/2017/advancedinformation.

O'Regan, J. K., \& Noë, A. (2001). What is it like to see: A sensorimotor theory of perceptual experience. Synthese, 129(1), 79-103.

Papineau, D. (1991). Correlations and causes. British Journal for the Philosophy of Science, 42(3), $397-412$.

Popper, K.R. (1965[1934]). The logic of scientific discovery. New York: Harper \& Row.

Psillos, S. (2002). Causation and explanation. Montreal \& Kingston: McGill-Queen's University Press.

Radder, H. (1996). In and about the World. Albany: State University of New York Press.

Radder, H. (2006). The world observed/the world conceived. Pittsburgh: University of Pittsburgh Press.

Radder, H. (2009). Science, technology and the science-technology relationship. In A. Meijers (Ed.), Philosophy of technology and engineering sciences (pp. 65-91). Amsterdam: Elsevier.

Radder, H. (2012[1984/1988]). The material realization of science: From Habermas to experimentation and referential realism, revised edition, with a new postscript. Dordrecht: Springer.

Russell, B. (1963[1917]). On the notion of cause. In B. Russell, Mysticism and logic. London: Unwin Books, 132-151.

Salmon, W. C. (1984). Scientific explanation and the causal structure of the world. Princeton: Princeton University Press.

Van Calmthout, M. (2016). De anticlimax van Einsteins gelijk [The anticlimax of Einstein being right]. De Volkskrant, August 20, 2016.

Van den Berg, J. (2015). Windmolen brengt telescoop in de war [Windmill interferes with telescope]. De Volkskrant, May 20, 2015.

Van der Heijden, J. (2018). Telescoop snoert molen de mond [Telescope silences windmill]. De Volkskrant, December 20, 2018.

Van Fraassen, B. C. (1980). The scientific image. Oxford: Clarendon Press.

Van Fraassen, B. C. (1989). Laws and symmetry. Oxford: Clarendon Press.

Wilson, J. (2006). Causality. In S. Sarkar \& J. Pfeifer (Eds.), The philosophy of science: An encyclopedia (Vol. 1, pp. 90-101). New York: Routledge.

Publisher's Note Springer Nature remains neutral with regard to jurisdictional claims in published maps and institutional affiliations. 